\title{
In Her Own Eyes: \\ Photovoice as an Innovative Methodology to Reach Disadvantaged Single Mothers
}

\author{
Sophie-Claire Valiquette-Tessier, Marie-Pier Vandette, and Julie Gosselin \\ University of Ottawa
}

\begin{abstract}
Photovoice is a photographic technique allowing people to identify, represent, and enhance their community by entrusting cameras to the hands of participants to enable them to capture issues central to their lives. However, few studies have used Photovoice with disadvantaged single mothers, and explicitly studied the impact of using this type of methodology with this population. Hence, the purpose of this study was to assess the impact of Photovoice with disadvantaged single mothers participating in the community-based program Toward Success. Results showed that participants experienced generally positive impacts, such as a sense of accomplishment and increased agency in their lives, and reported no negative impacts.
\end{abstract}

Keywords: Photovoice, single mothers, social inclusion, participatory methods

\section{RÉSUMÉ}

Photovoice consiste en une technique utilisant la photographie afin de permettre les participants et participantes d'identifier, de représenter et d'améliorer leur communauté, et ce en leur remettant des caméras pour capter les enjeux qui sont centraux dans leur vie. Rares sont les études ayant employé Photovoice chez des mères monoparentales défavorisées pour s'attarder aux impacts d'une telle méthodologie auprès de cette population. Ainsi, cette étude vise à évaluer l'impact de Photovoice auprès de 6 mères monoparentales participant au programme communautaire Vers la réussite. Les participantes ont rapporté des impacts généralement positifs, notamment un sentiment d'accomplissement et un désir d'agir comme agentes du changement, alors qu'aucun impact négatif n'a été noté.

Mots-clés : Photovoice, mères monoparentales, inclusion sociale, méthode participative

Sophie-Claire Valiquette-Tessier, School of Psychology, University of Ottawa; Marie-Pier Vandette, School of Psychology, University of Ottawa; Julie Gosselin, School of Psychology, University of Ottawa.

Correspondence concerning this article should be addressed to Julie Gosselin, School of Psychology, University of Ottawa, 136 Jean-Jacques Lussier \#4013, Ottawa, ON K1N 6N5. Email: jgosseli@uottawa.ca 
With the increasing availability and ease of use of technologies including camera phones, digital cameras, video recorders, and microblogging, many qualitative researchers are embracing these tools to share information, build knowledge, and convey understanding (Gibbs, Friese, \& Mangabeira, 2002; Pink, Kurti, \& Afonso, 2004). Moreover, research designs that employ such technologies can give a voice to participants with low literacy skills, who are stigmatized or who present an invisible illness or live in the margins of society (Villagran, 2011). Therefore, communication technologies constitute a mean for researchers and vulnerable populations to co-create and form a partnership though community-based participatory research (CBPR). CBPR recognizes that community members are equal partners in problem definition, methodological development, data collection/analysis, and dissemination of findings (Fisher \& Ball, 2003). Photovoice, a method highly consistent with CBPR principles, acknowledges the expertise of participants by reducing power differentials, focusing on community strengths rather than deficits, and compelling participants to reflect on their own experiences (Israel, Schultz, Parker, \& Becker, 1998; Minkler \& Wallerstein, 2003; Tsey et al., 2007).

\section{Photovoice Technique}

Photovoice is a technique whereby participants identify, represent, and enhance their community through photographs and narratives (Wang \& Burris, 1997). In practice, cameras are provided to participants so that they may document their realities, share their stories, and target recurrent issues in their lives (Wang, MorrelSamuels, \& Pestronk, 2004). Photovoice was introduced by Caroline Wang and Mary Ann Buris in 1994 and first applied in the Ford Foundation-supported Women's Reproductive Health and Development Program in Yunnan, China. The two researchers had the following intentions: (a) enable the women to record their community's strengths and concerns, (b) promote critical dialogue and knowledge via group discussions, and (c) initiate grassroots social change by reaching policy-makers (Wang \& Burris, 1997).

The Photovoice methodology relies on three theoretical underpinnings: documentary photography (Rose, 1997), feminist theory (Hesse-Biber \& Yaiser, 2004), and Paulo Freire's (1970) theory of critical consciousness. The first is based on the premise that entrusting cameras to those who would normally not have access to one can be empowering. The second takes into account patriarchal power and criticizes the assumptions concerning women's lives and the political, economic, and social systems and ideologies that shape society. The focus is on women's subjective experiences, considering diversity, partnership in research, and issues of power, representation, and voice in relation to gender (Wang, 1999). The third fuels critical consciousness by engaging individuals in questioning their historical-social situation (Castleden \& Garvin, 2008; Frohmann, 2005). It stresses the importance of dialogue within the community, which may lead to transformation and liberation (Duffy, 2010).

Photographs carry a message sometimes more striking than words since they exploit the emotional power of images, symbols, and metaphors (Wang \& Burris, 1997). Photovoice may therefore act as a catalyst for discussion and co-learning through which participants may develop a profound understanding of a common reality. It offers an opportunity to expose participants' experiences to their community and, in some cases, fosters empowerment so that participants can become advocates for change (Leipert, 2010). Furthermore, this method limits distortion of fitting data into a predetermined paradigm by hosting a forum for the presentation of what matters to people and what significance they attribute to their realities (Glik, Gordon, Ward, Kouame, \& Guessan, 1988; Wang, Morrel-Samuels, \& Pestronk, 2004). 
Photovoice has been employed for evaluation, especially for participatory needs assessment, with a variety of populations including homeless people (Wang, Cash, \& Powers, 2000), children and youth (Fitzgerald, Bunde-Birouste, \& Webster, 2009; Gant et al., 2009; Goodhart et al., 2006; Wang, 2006; Wilson, Minkler, Dasho, Wallerstein, \& Martin, 2008), older adults (Baker \& Wang, 2006; Lockett, Willis, \& Edwards, 2005), groups of women (Booth \& Booth, 2003; McIntyre, 2003; Moffitt \& Vollman, 2004; Valera, Gallin, Schuk, \& Davis, 2010; Vaughn, Forbes, \& Howell, 2009; Wang, 1999; Wang \& Pies, 2004), and those living with a specific illness (Aubeeluck \& Buchanan, 2006; Gosselink \& Myllykangas, 2007; Hergenrather, Rhodes, \& Clark, 2006).

A study carried out by Duffy (2011) demonstrated that Photovoice was particularly effective with women. Between 2005 and 2007, in the city of Moncton (New Brunswick, Canada), seven single mothers took part in a community health assessment using Photovoice. Results revealed an increased sense of empowerment among the mothers. They especially reported having more control over their lives, feeling more confident in themselves, and thinking more positively as a result of participating in the Photovoice project (Duffy, 2011). Duffy (2010) conducted another Photovoice study on the health and well-being determinants of lone mothers. Through a formative evaluation, the researcher asked the women how the project affected their lives. They reported a sense of belonging, more confidence in themselves, increased employment opportunities, improved self-worth, and moving forward instead of worrying about the past (Duffy, 2010).

Results from Duffy's $(2010,2011)$ studies are consistent with those from earlier evaluations of the Photovoice technique. For example, Foster-Fishman, Nowell, and Deacon (2005) found that two processes can facilitate participants' empowerment: documenting community strengths and concerns with photographs, and discussing their photographs and experiences with other community members. Participants also reported an increased sense of control over their lives, the emergence of awareness, and a desire to become agents of community change. Similarly, Carlson, Engebretson, and Chamberlain (2006) analyzed dozens of photographs, stories, group discussion transcripts, and journals. They discovered that Photovoice activated critical consciousness as well as participation, thereby facilitating empowerment.

\section{Single Motherhood in Canada}

In Canada, there were 1.3 million single parent families in 2011 , representing $16 \%$ of all families. Eighty percent of these families were headed by a woman. In other words, for each single parent household headed by a father, there were four households headed by a mother (Statistics Canada, 2012). The increased prevalence of single parent families has led to a growing field of study interested in associated child developmental outcomes. Unfortunately, the comparison with intact families has highlighted a deficit for those living and growing up in single mother households. Indeed, although the research on single motherhood is abundant and diversified, it generally focuses on the financial instability and the impacts related to growing up in a single mother family. An avenue to improve the living conditions of those families and facilitate the children's long-term adjustment consists of promoting their family's social inclusion and supporting mothers in their parental role. Yet we know very little about the manner in which these processes can lead to positive outcomes since mothers' own experiences in facing stressors and cultivating resilience have not been the focus of much research (Arendell, 2000). 


\section{Our Study}

The present study is the second part of a larger project realized among disadvantaged single mothers invested in Toward Success, a three-month community-based program that aims to enhance their social inclusion, parenting, and coping skills. Participants attend for a total of 6 hours per week during the duration of the program. The first part of this study took place in the fall of 2012 and focused on data collection using Photovoice to document the participants' experience as they completed the program. The data generated gave a voice to the women by promoting their understanding of a common social reality. This data collection yielded a number of interesting findings currently under review (Vandette, Valiquette-Tessier, \& Gosselin, in press). The second part of this study now explores how the participants experienced the Photovoice project, how the use of this methodology may have impacted their experience of the program they were completing at the time, and how it may have contributed to their experience of empowerment. Two central questions guided this inquiry:

1. What are the impacts of using Photovoice in the context of participants completing a community program, such as Toward Success?

2. How does Photovoice foster these impacts?

\section{METHOD}

\section{Participants}

Six single mothers took part in this study (mean age $=38)$. More than half $(n=4)$ were natives of Gatineau (Quebec, Canada), with an average of less than 2 children each under 14 years old, lived in a disadvantaged socioeconomic situation with an annual income of less than $\$ 14,999$, received social assistance and reported problems with child protection services, and/or experienced domestic violence and/or abuse of drugs/alcohol. The data collection for this study took place while the participants were completing the program Toward Success based in Gatineau. Toward Success is a 72-hour program financed by Emploi Québec. Emploi Québec offers a range of services addressed to the general population or to specific client groups. Two of the main services are employment assistance (e.g., services and information for people looking for work) and individual and family assistance (e.g., financial assistance and social support; Gouvernement du Québec, 2013a).

The program was first introduced when a lack of appropriate services targeted to single mothers in the Outaouais region was identified by the Association des Familles Monoparentales et Recomposées de l'Outaouais (AFMRO), which created the program in 1999. At the time, a social worker collaborated with the AFMRO to develop the program's curriculum. The curriculum comprises nine modules: self-esteem, anger and stress management, divorce/separation, stepfamily life, family harmony, time management, intimacy and sexuality, anxiety, and domestic violence. The modules are taught by an educative coach who has worked for 20 years with populations of abused women. In addition to the didactic material presented and discussed in class, an agent from the local employment centre meets with participants of the program to provide vocational counselling. The centre offers services and resources regarding employment assistance or last-resort financial assistance (Gouvernement du Québec, 2013b). In the context of this program, the group also visits an adult training centre located in the community where individuals may receive additional skills training to improve their employability. 


\section{Procedure}

After obtaining the approval of the University of Ottawa Research Ethics Board, this study was presented to the director of the Association des Familles Monoparentales et Recomposées de l'Outaouais (AFMRO). She expressed interest in the project and recommended that we recruit participants among the single mothers taking part in the association's program Toward Success. The project consisted of seven meetings that took place from September to December 2012. During the first meeting, the researchers explained the Photovoice technique to the potential participants and gave them the consent form to review. They had 2 weeks to read it and familiarize themselves with all aspects of their participation in the study. Mothers were informed that their identity would remain protected. Indeed, only the researchers would access the data generated during the research process (audio recordings, socio-demographic questionnaires, posters, logbooks, and photos), and all of the above would be secured under lock in the Stepfamily Research Laboratory at the University of Ottawa. Moreover, participants were made aware that their names would never be revealed since pseudonyms would be used. At the next meeting, the mothers willing to take part in the Photovoice project signed the consent form and filled out the socio-demographic questionnaire. At that point, each participant was provided with a digital camera and trained in the ethics of taking photographs. The training then moved to mechanical aspects of camera use (Baker \& Wang, 2006; Foster-Fishman et al., 2005; Goodhart et al., 2006; Moffitt \& Vollman, 2004; Vaughn et al., 2009).

Afterwards, participants had 2 weeks to take photographs and fill out a logbook documenting each photograph. During the third meeting, the mothers reviewed their pictures and chose the six most significant in representing their current reality. The participants were then given an additional 2 weeks to take more photographs and complete the logbook. The fourth meeting mirrored the third, and at that point participants chose a final set of six pictures. The facilitators also gave instructions for the next step: to create an individual poster, showing each mother's personal work. Participants had 2 weeks to make their posters (Baker \& Wang, 2006; Foster-Fishman et al., 2005; Goodhart et al., 2006; Moffitt \& Vollman, 2004; Vaughn et al., 2009).

The fifth and sixth meetings were filmed and dedicated to the poster presentations followed by a group discussion about the themes emerging from the pictures chosen. During the last meeting, which was also recorded, a semi-structured interview was carried out to discuss the Photovoice process. Semi-structured interview questions guided the discussion: (a) What did you like about your Photovoice experience? (b) What did you dislike about your Photovoice experience? (c) How did you feel before/while/after participating in the Photovoice project?

\section{Data Analysis}

Logbooks, audio recordings of group discussions, and field notes were analyzed following Thomas's (2006) inductive approach. This analytical strategy is adapted to the needs of program evaluation since it is guided by specific research objectives/questions about the domains to be investigated. Even if the findings

are influenced by the research questions, the analysis is not guided by a priori expectations. Therefore, the findings emerge from the analysis of the raw data. This approach enables researchers to (a) condense extensive raw data into a summary format, (b) link the data with the research objectives, and (c) produce reliable 
and valid findings by following a systematic set of procedures (Thomas, 2006). To ensure trustworthiness and representativeness, the analysis included all of the data generated: the final set of photos (six photos per participant for a total of 36 photos); logbooks of each participant; and transcripts from the poster presentations, group discussions, and semi-structured interviews. All the information was gathered in a single database in NVivo 10 (QSR International, 2012), which permits the coding of photos as well as text. Data were first organized by question and afterwards by theme.

Data analysis was completed by following a systematic procedure comprising four stages. First, all audio-recording material was transcribed verbatim and read many times by the researchers in order to be familiar with the content (Apostolidis, 2006; Thomas, 2006). Second, the main researcher reviewed the logbooks and photos to identify text segments and images relevant to the research questions. A codebook was progressively elaborated in a way that more general categories were likely to come from the evaluation questions, and specific categories were derived from multiple readings of the raw data. To check for consistency, a second database with the same information was created (all the transcripts, logbooks, and photos). Another researcher assigned sections of the text and individual photos to the categories developed by the first coder. Next, one last database including $25 \%$ of the data was generated. A last coder took the category descriptions of the final codebook and matched these with the data belonging in those categories. To ensure rigour and trustworthiness, the material coded by the three researchers was compared with a coding query comparison in NVivo 10, and an inter-rater agreement was calculated. For all the themes, the agreement was never less than $92 \%$, showing little variance and high consistency. Finally, the participants were reunited one last time in a focus group where they validated the findings and interpretations made by the research team. This final step enhanced the credibility of findings (Thomas, 2006). Only the themes discussed by more than one mother are presented in the Results section to provide a reliable picture of the participants' experiences with Photovoice.

\section{RESULTS}

1. What are the impacts of using Photovoice in the context of participants' completing a community program, such as Toward Success?

\section{Sense of Accomplishment}

According to all participants, taking part in Photovoice presented an important personal challenge. They faced their fears, particularly talking before a group and working mostly alone. This situation generated anxiety for many participants since they felt exposed to others' judgments.

For me it was to do it alone. Because I always, when I do something, I need others' approval. (Micheline)

Even if we know them and we know that they won't judge us, we judge automatically. (Cristelle)

However, persevering through the project gave all participants a sense of accomplishment. During the poster presentations and group discussions, participants received positive feedback that contributed to generating a feeling of pride in their work. Furthermore, all of them expressed satisfaction concerning their 
personal growth during the Photovoice project. For example, a participant was impressed and very pleased with herself when one facilitator compared her poster to journalistic coverage.

For me it was when I saw your poster... Then, I was like "Oh my God! I'm not on the right track." When one of you three told me that my poster was done in a journalistic way ... $500 \mathrm{lbs}$ of pressure were taken off my shoulders. Wow! OK, this means it was OK. (Marion)

Photovoice also challenged participants to step outside their comfort zone. Indeed, instead of sitting on the fence and staying silent, they had to form opinions and develop critical thinking skills. As a result, they noticed that their ability to effectively communicate increased. Most participants reported feeling more confident in sharing ideas in a group context, doing stand-alone presentations, and showing assertiveness in their lives.

Just to talk ... because I'm very shy, and I'm not able to speak, and I'm not able to confide myself, and I'm not able to say "No." After the poster presentation, I went outside and I said: "I was able to do it and my ears didn't even burn." So, for me it was then that I had $100 \%$ more, for me I was able to do it. (Marion)

Every report card I have, if I had an oral presentation, I was not at school. I went to do a self-esteem class, or I don't know, once. They asked me to say my name in front on the group. I ended up rolling my shirt so much it was up to here [pointing at her shoulders]. Good thing that I had the poster in my hands. But no, just to do that, it gave me such a personal accomplishment. (Cristelle)

It allowed me to see that I was able to do something until the end. I tried at school three or four times but it didn't work. I told myself: "I will never be able to finish something I started." Now, I did and I told myself I did not quit. I gave it my best like I was supposed to. When you want to, you can do everything! (Micheline)

\section{Deeper Understanding of Participants' Self and Own Reality}

Through taking photographs, sharing stories, and connecting with members of their community, all participants developed a deeper understanding of their personal circumstances and the conditions surrounding them. Indeed, participants reported that the Photovoice technique compelled them to dissect and explain the meaning of every photograph.

I think I understood my environment better by taking photos. I told myself: "Well, oh my God this is what I live, it's like that, well it's part of that." I think it helped me even more to represent, to understand what I was living. (Nancy)

It's like when we see a painting ... we try to analyze the painter. We ask ourselves why he painted it like that. That is what the picture does, I think. That's the difference between this and a questionnaire where you answer "yes" or "no." You deconstruct it, you explain it, you go further. (Samantha)

Additionally, Toward Success gave participants an opportunity to connect with themselves and with others who share similar life experiences. Participants all reported agreeing to complete the program in order to work on particular aspects of their personal lives, and in the process they discovered underlying problems.

You know, we're all here to work on something. Personally, in my head, my self-esteem was so low. It turned out it wasn't that bad. She [the educative coach] made us work on things that brought up wounds we didn't think we had. (Cristelle)

Participants reported that the program helped them figure out who they are as a person and parent, and accept and have more compassion toward themselves. Before Toward Success, most of them would go to 
great lengths to please others - often by subjugating their own opinions and needs. They felt they could never be entirely authentic with others if they wanted to have some of their needs met. However, following completion of the program and the Photovoice project, many reported that loving one's self is the first step to being loved authentically.

Well before, I didn't like myself. I did everything to please others. If I was trying to be her friend and she was growing her hair, well I would grow my hair too because for me that was how she would accept me. I was always under the impression that I couldn't be myself, that I had to be someone else to be loved. Today, I realized that I like myself and that people will like me even more because I project something good. I project love. (Micheline)

Participants' improved self-knowledge and self-acceptance impacted Photovoice. They were less scared of representing their realities because they had a better understanding of what to articulate and how to do so. This particular influence of the program was also reflected in their capacity to open up and formulate their own perspective during group discussions.

I had a lot of difficulty in being assertive. I was very closed up, I didn't talk, didn't say my opinions, I didn't say anything. I was in my corner. I let others speak for me. But now it's over, that's over now, I take my rightful place. (Nancy)

\section{Increased Optimism}

As a result of their involvement with Photovoice, all the participants noted significant growth and change in their way of perceiving life. Before engaging in the project, most participants confined themselves to negative thoughts, seeing only what was wrong in their everyday routine (e.g., lack of money, overwhelming responsibilities, difficulty finding a job). But documenting their reality and reflecting on it made them notice the positive facets of their lives as well. For example, they showed gratitude for their family and friends, instead of focusing on what they lacked. Participants are conscious of the challenges they experience, but they also reported choosing not to focus as much on these aspects from this point on. They reported that focusing on the negative aspects of their lives aggravates the situation by making them feel negatively about themselves and fostering hopelessness.

It makes us realize that yes there is some negative, but there is also some positive that needs to be acknowledged. For me, it made me realize that always playing the victim will make it harder for me. Look, I have friends, I have family, I have my little boy, what do you want more? Yes, it's not easy, but I'm still here. (Micheline)

That was my main thematic ... To show that after darkness, it is possible to have a life filled with colours. (Nancy)

However, this increased optimism cannot be strictly attributed to Photovoice. Indeed, throughout the 72-hour program, participants' vision of their own life evolved. While their perceptions and attitudes were mostly pessimistic at the start of the course, they became more positive as they progressed through Toward Success. Participants reported that it was as if they saw the light at the end of the tunnel and could now express the hope of starting a new life. Participants felt the program gave them courage to maintain their commitment to family and friends, and more importantly to trust in their own potential. In fact, the message 
that they are capable was repeated to them often throughout their involvement, and appeared to have slowly sunk in. This transformation was reflected in their photographs, which gradually shifted from portraying darker scenarios to depicting joy, hope, and perseverance.

So for me, with the examples that you gave us, I already had an idea. For the second meeting, I had chosen ideas and photo ideas with language ideas. But, after our meeting, I noticed that it turned too much around depression. When the end of the project arrived, I said: "No, somewhere there is still some good in our lives." Yes, we struggle, that's true, that's the reality. But at the same time, we have moments when everything goes well. But if I come back to my pictures, at the beginning it was too dark. I wanted at the same time to finish my project on the other side of the coin. (Samantha)

I also wanted to make a more negative poster. Show my empty fridge, but at the last minute, I changed everything. I said, "No! That's not what I want to show, that's not it, I have some good in my life." And I showed the good.... Because like I told you, I was two months in psychiatry, and I saw a lot of negative and I saw a lot of darkness. I don't want that anymore. (Nancy)

In an individual interview with the research team, the educative coach leading Toward Success said that she believed the program and Photovoice were complementary. She reported to the research team that the program was beneficial to prepare participants for the project and that Photovoice reinforced the application of what they learned in class. She was also convinced that without the course, participants' photographs would have been more negative. She reported that participants were aware of their challenges, but that they also acknowledged both sides of their experience in a more nuanced manner than before.

It was complementarity I think. I think one without the other doesn't work because there would have been too many very dark, very grey, very pessimistic images. It would have been quite another exhibit that you would have had without that training. (Educative coach)

\section{Sense of Being Unburdened}

Participants also reported experiencing a liberating feeling after completing the Photovoice project. Analyzing their community's assets and concerns through critical dialogue gave all of them an opportunity to externalize their feelings, buried or not, as well as to connect with themselves and gain insights into why they felt the way they did. Even if the problems they defined were still present, explicitly acknowledging them yielded relief. Despite the challenges encountered throughout the Photovoice process, participants described it as revitalizing in the long run. This feeling was enhanced by participants' increased self-esteem.

Just to have done it.... After, I was feeling as if I was on a high. I felt as if I had taken something very strong. I was telling myself: "Wow! I did it! I did it!" I think that everyone felt like they had a big ball of energy inside of them. Because we felt so much pressure on our shoulders. We were telling ourselves, "We're not good. No, that's not what we were supposed to do. Ah, that's not what she wanted. It's not this, it's not that." After we finished, it was like an evaluation. The same as after giving birth, you're liberated, you're like: "Ah, it's done." It was really magical. (Cristelle)

We felt liberated after talking. I feel liberated. My problem is still there, but it helped me to feel liberated. (Samantha)

All the participants reported entering the program with low self-esteem and a sense of emotional emptiness. As the weeks progressed, and with the help of the Toward Success educative coach, they 
became more sure of themselves, which in turn influenced their photographs, reflections, and interactions. Hence they became less shy when speaking during group discussions and oral presentations. They also questioned their work less and showed more confidence when it came to analyzing a picture or explaining their conclusions.

Photovoice and the course together were like a therapy, a detox. You understand what I mean? You come in here completely destroyed and you come out with so much more confidence in yourself. It's like a relief. (Micheline)

The shyness too, it takes a lot away. If we didn't do the course Toward Success, we would probably not have done the project. (Josy)

But we did it because it came with the course. Without the course, we wouldn't have done it the same way. We wouldn't have told you what we told you the way we told you. We would have said "tetetetete"... stuttering and becoming red like a tomato. (Marion)

I think the pictures follow my personal process. The more I went forward, the more self-esteem I had, the more I found myself pretty, the more I would tell myself. And the photos, that's really it. I learned to separate, to not put everything in the same boat. It really goes with my personal process. (Micheline)

\section{Increased Sense of Agency}

Finally, participants reported feeling empowered through Photovoice. They interpreted the interest shown by the research team in their lives as a sign that they have something meaningful to convey. As their specific realities were acknowledged, participants felt pulled out of the shadow. As a result, they felt empowered to bring change within their community by acting as leaders. For more than half of the participants, Photovoice made them realize that their increased awareness about the implications of the conditions surrounding them could be a powerful tool to help others. Moreover, conditions that were previously viewed as usual were now seen as requiring change (e.g., insalubrity of apartment building). Thus, one particular participant expressed her sense of responsibility toward younger generations and her desire to become a caretaker of her own community.

And by looking back, I realized it. There is a way that we can do, I try to think of tons of things and then I write, I write the little ideas. But there is a way, it has to be done because then it is the younger generations who are impacted. They are 7-8 years old and they fight, but they see their parents doing it. They almost have to be taken in charge, to give them a hand, come beside the wall, come, I'll bring you to the other side. And trying to find like, there are a lot of ways that we can try, like things that we can do. It's the government, it's the money that is missing ... and the people who are really anchored, so anchored that they don't want to change to start over. But it's people like us, who decide to take a course, who give themselves a kick in the butt, and who tell themselves we're starting over. It's never too late. (Marion)

\section{How does Photovoice foster these impacts?}

During the group discussions, participants spoke about how certain aspects of this method fostered the impacts identified here. Three aspects of the Photovoice technique appear to have been instrumental in creating these impacts: treating participants as experts on their own lives, having a flexible methodology, and fostering solidarity among participants. 


\section{Experts on Their Own Lives}

In the context of this project, the Photovoice methodology enabled participants to share their expertise and be positively impacted. First, facilitators reiterated many times that participants' stories were highly salient. For example, during the first meeting and after each group discussion, participants were reminded of the importance of their realities. Also, they were shown examples of Photovoice conducted with diverse populations to demonstrate that everyday people have important things to say. In this way, participants felt that facilitators trusted in their capacity to participate, which facilitated their involvement in the project as well as the emergence of positive outcomes.

When you asked me that, I felt good. I told myself: "My God, there is somebody who trusts me, who thinks that I have something important to say." I told myself: "My God, I think that I never have anything interesting to say, and now someone I don't know thinks that I have something interesting to say." I really felt like I was trusted. For me it was the trust. (Micheline)

Second, the participants were given complete autonomy to capture the images that they considered significant and to tell their stories. Only three broad questions guided the process: (a) What are the experiences and challenges of single mothers living in a disadvantaged situation? (b) How do single mothers perceive themselves? (c) What place do single mothers occupy in their community and do they feel included within their community? Accordingly, participants were provided considerable latitude throughout the different phases of the project. Participants reported that this approach contributed to the emergence of positive repercussions because it was empowering and more fulfilling than traditional methods such as questionnaires. Participants showed facilitators what mattered to them instead of selecting from a limited number of responses in a questionnaire.

Well, anyway, I think that it's better than questionnaires, because questionnaires often they will, they almost go get the answers you want to hear. But here we take photographs of what is there, of what we have, so it's in our faces. We talk about that and not other things so it's harder to embellish or to make things up. (Nancy)

\section{Methodological Flexibility}

Participants have different preferences when it comes to expressing themselves. While some are comfortable with oral expression, others feel more at ease when writing. Participants believed that Photovoice was suitable for both types of participants because it offers both written and verbal communication as vehicles to shed light on photographs. Participants added that letting them choose their preferred mode of thinking promoted reflection and positive consequences, specifically a deeper understanding of their realities and a liberating feeling. One participant mentioned that she enjoyed filling out the logbook for each picture. When she was unsure of how to explain a photograph, she discussed it with the person she photographed and afterwards translated it into her own words via writing.

To write, it was OK, it came out well, but taking the photos was tough. I found that what I had written didn't represent the image. So that is why there are photos of Jammie [participant's son], and it was easier to let him tell me how he felt and why he asked me to take those pictures. He could tell me: "I feel like this, I feel like that." So then I would write what he told me. For example, when he was in the staircase, it's him that told me, "Mommy, I want to show that I'm a prisoner in my own body." Then I figured, "OK, you are a prisoner ... Why is that?" He replied, "Because I'm overweight. I don't like it. I get intimidated at school. I get teased." ... I could then transform the sentences in order for them to make sense. (Cristelle) 
Also, since many participants prefer visual stimuli, they appreciated the concrete and creative nature of photographs, especially in comparison with questionnaires. They found taking photographs more stimulating because the final result was immediate and increased their sense of accomplishment.

Josy: I preferred taking photos.

Researcher: Why is it different to take pictures?

Josy: I find it stimulating, because you see it right away, it's concrete. You have the results there. But when you write, it's always long.

Finally, Photovoice appears well adapted for participants who may have difficulty finding a deeper meaning in and understanding of their own reality. Facilitators assisted participants in interpreting their photographs by using the SHOWeD acronym (What do you see here? What is happening? How does this relate to our lives? Why does this problem or strength exist? What can we do about it?" (Wang, 1999). These questions acted as a mechanism to facilitate dialogue and bring about increased understanding about what the photographs depicted.

It's her [pointing to one of the facilitators] who gave me things to say. Because then she said, "What does Fumanza represent?"

"A princess."

"But why a princess?"

"Because in real life, you can look like a princess, you'll be valued. But if you don't look like a princess, you'll get shut down." (Cristelle)

I really learnt how to deconstruct the different meanings behind the photos and not put everything in the same boat. (Josy)

\section{Solidarity among Participants}

Completing a Photovoice project in a group setting, with other mothers willing to ameliorate their living situation, revealed itself to be very motivating for participants. The project created a positive environment conducive to their increased optimism. Furthermore, the experiences, stories, and challenges that they shared brought participants closer together. Old friendships were solidified and new ones were built. These relationships enhanced participants' sense of belonging to their Toward Success group. When they were discouraged, they turned to each other, which encouraged them to persevere. Participants reported that group solidarity contributed to exchanges between them and facilitated deeper understanding of the conditions surrounding their community. It also seems that having support from other members of the group helped participants to open up and experience the relief that can come from sharing. Finally, being part of a unified group gave a few participants the desire to bring change to their community.

We're with people who share our vision, who want to help themselves. Usually, we're with people who are more pessimistic, who feel sorry for themselves. But here, with a group that wants to get through, it's as if we made a movement for something else and we helped each other to be more positive. We want to keep the negative out of our lives. (Nancy)

It's like we created a movement towards change and we helped and supported each other during the entire process. (Josy) 


\section{DISCUSSION}

Community-based participatory research (CBPR) gives importance to how individuals living on the margin of society make sense of their world and interpret it (Plunkett, Leipert, \& Ray, 2012). Photovoice, a specific CBPR methodology, has been used with different projects involving marginalized populations. At the same time, fewer studies have evaluated Photovoice's impacts on participants to contribute to the body of methodological literature (Castleden \& Garvin, 2008). Generating such knowledge remains critical in order to adapt this methodology as an intentional form of intervention. Photovoice studies are particularly relevant since researchers face a growing demand for methods or approaches that are socially useful and designed to meet community needs, assess local questions, and consider insiders' concerns (Foster-Fishman et al., 2005). Therefore, the purpose of this study was to highlight Photovoice's impacts on the participants, how these impacts emerged, and what influence the program Toward Success had on the Photovoice process and vice versa.

Although our sample size was small, it is recommended that between 6 and 12 participants are required to run an effective Photovoice project (Work Group for Community Health and Development, 2013). Indeed, the data gathered from Photovoice studies can bring out information that could have been missed with larger qualitative samples. Small samples allow in-depth exploration of the experiences and perspectives of the participants, affording rich insights into some communities otherwise ignored (Hergenrather, Rhodes, Cowan, Bardhoshi, \& Pula, 2009). Our overall findings converge with those of other studies describing Photovoice's impacts. On one hand, our results relate to the concept of personal growth discussed by Wang et al. (2000), Lykes (2001), and Foster-Fishman and colleagues (2005). Participants reported that persevering through the project generated a sense of accomplishment and pride because they faced their fears, for example, by communicating through oral, written, and visual means before a group. All the participants compared the Photovoice project and the program Toward Success to a fulfilling personal journey. They reported connecting more authentically with themselves, which contributed to their increased self-knowledge, self-acceptance, assertiveness, and self-esteem as well as to a general metamorphosis in their way of approaching their life circumstances.

Our finding of increased optimism was also reported by the lone mothers participating in Duffy's (2010) project. Participants from both studies examined their lives throughout Photovoice and started to appreciate the good, and believe in a better future. Our findings are also consistent with Lykes's (2001) and Foster-Fishman et al.'s (2005) notion of critical consciousness. Participants reflected on their photographs and therefore deepened their understanding of their lives. Consequently, many of them developed increased awareness about their realities and a desire to become role models for the next generation or change agents within their communities. Both of these impacts - personal growth and critical consciousness - are linked with Keiffer's (1984) conceptualization of empowerment defined as improved skills and efficacy as well as expanded awareness about participants' surroundings.

The factors that produced such impacts are also consistent with previous studies. As mentioned by Berman, Ford-Bilboe, Moutrey, and Cekic (2001), Gaventa and Cornwall (2001), and Foster-Fishman et al. (2005), giving participants the opportunity to reflect on their lives and build their own narratives facilitated the emergence of positive impacts. Enabling them to play a central role and share their expertise fostered a sense of trust toward the research team. The self-determination integral to the project was interpreted by 
participants as a demonstration of the researchers' trust in their knowledge and abilities. Being able to choose their preferred media for communicating (writing, verbal, and/or photos) made it easier for participants to reflect on their living situation. Facilitators also helped participants to interpret their photographs through a series of questions (the SHOWeD method discussed earlier). Therefore, this context stimulated open exchanges, enriched through diverse perspectives and experiences, which in turn permitted the emergence of positive impacts (Foster-Fishman et al., 2005).

Our findings are highly consistent with those of other studies that have explored the impact of Photovoice. However, the impacts reported here should be considered short-term outcomes, and it is not yet clear whether they will persist and/or generalize to other aspects of participants' lives. Hence, more attention must continue to be devoted to the medium- to long-term impact of participatory research designs, since community-based methods can have intervention-like effects on participants. There is a need to select appropriate methods depending on the targeted population and considering the desired effects on individuals and the larger community (Foster-Fishman et al., 2005). Furthermore, it is necessary to continue to consider the strategy used for assessing impact when conducting this type of research.

In conclusion, this study explored how disadvantaged single mothers experienced a Photovoice project, and how the use of this methodology impacted their participation in the program Toward Success. It was found that the Photovoice technique acted as a catalyst bringing impacts ranging from an increased sense of accomplishment to a deeper understanding of the reality of participants' daily lives. In turn, those impacts influenced participants' journeys while completing the program Toward Success in that they developed a more nuanced and empowering perception of themselves and their lives. Examining the relationships between innovative methodologies such as Photovoice and participants' enhanced competencies and empowerment reminds researchers to be mindful when conceptualizing and selecting a research design and/or methodology. Indeed, research can act as an intervention and serve the communities that take part. In doing so, researchers can support community empowerment by focusing on participants' strengths, as well as their challenges, and by helping communities find adaptive and relevant solutions to their own difficulties.

\section{NOTE}

1. Names have been changed.

\section{REFERENCES}

Apostolidis, T. (2006). Représentations sociales et triangulation : Une application en psychologie sociale de la santé. Psicologia: Teoria e Pesquisa, 22, 211-226. doi:10.1590/S0102-37722006000200011

Arendell, T. (2000). Conceiving and investigating motherhood: The decade's scholarship. Journal of Marriage and Family, 62, 1192-1207. doi:10.1111/j.1741-3737.2000.01192.x

Aubeeluck, A., \& Buchanan, H. (2006). Capturing the Huntington's disease spousal carer experience: A preliminary investigation using the "photovoice" method. Dementia, 5, 95-116. doi:10.1177/1471301206059757

Baker, T. A., \& Wang, C. C. (2006). Photovoice: Use of a participatory action research method to explore the chronic pain experience in older adults. Qualitative Health Research, 16, 1405-1413. doi: 10.1177/1049732306293846

Berman, H., Ford-Bilboe, M., Moutrey, B., \& Cekic, S. (2001). Portraits of pain and promise: A photographic study of Bosnian youth. Canadian Journal of Nursing Research, 32, 21-41.

Booth, T., \& Booth, W. (2003). In the frame: Photovoice and mothers with learning difficulties. Disability \& Society, 18, 431-442. doi:10.1080/0968759032000080986 
Carlson, E. D., Engebretson, J., \& Chamberlain, R. M. (2006). Photovoice as a social process of critical consciousness. Qualitative Health Research, 16(6), 836-852. doi:10.1177/1049732306287525

Castleden, H., \& Garvin, T. (2008). Modifying Photovoice for community-based participatory Indigenous research. Social Science \& Medicine, 66, 1393-1405. doi:10.1016/j.socscimed.2007.11.030

Duffy, L. (2010). Hidden heroines: Lone mothers assessing community health using Photovoice. Health Promotion Practice, 11(6), 788-797. doi:10.1177/1524839908324779

Duffy, L. (2011). Step-by-step we are stronger: Women's empowerment through Photovoice. Journal of Community Health Nursing, 28, 105-116. doi:10.1080/07370016.2011.564070

Fisher, P., \& Ball, T. (2003). Tribal participatory research: Mechanisms of a collaborative model. American Journal of Community Psychology, 32(3-4), 207-216. doi:10.1023/B:AJCP.0000004742.39858.c5

Fitzgerald, E., Bunde-Birouste, A., \& Webster, A. (2009). Through the eyes of children: Engaging primary school-aged children in creating supportive school environment for physical activity and nutrition. Health Promotion Journal of Australia, 20, 127-132.

Foster-Fishman, P., Nowell, B., \& Deacon, Z. (2005). Using methods that matter: The impact of reflection, dialogue, and voice. American Journal of Community Psychology, 36(3-4), 275-291. doi:0.1007/s10464-005-8626-y

Freire, P. (1970). Pedagogy of the oppressed. New York: Herder and Herder.

Frohmann, L. (2005). The framing safety project. Violence against Women, 11(11), 1396-1419. doi: $10.1177 / 1077801205280271$

Gant, L., Shimshock, K., Allen-Meares, P., Smith, L., Miller, P., Hollingsworth, L., \& Shanks, T. (2009). Effects of Photovoice: Civic engagement among older youth in urban communities. Journal of Community Practice, 17, 358-376. doi:10.1080/10705420903300074

Gaventa, J., \& Cornwall, A. (2001). Power and knowledge. In P. Reason \& H. Bradbury (Eds.), Handbook of action research: Participative inquiry \& practice (pp. 70-80). London, England: Sage.

Gibbs, G. R., Friese, S., \& Mangabeira, W. C. (2002). The use of new technology in qualitative research. Forum: Qualitative Social Research, 3(2). Retrieved from http://www.qualitative-research.net/fqs-texte/2-02/2-02hrsg-e. htm

Glik, D., Gordon, A., Ward, W., Kouame, K., \& Guessan, M. (1988). Focus group methods for formative research in child survival: An Ivoirian example. International Quarterly of Community Health Education, 8(4), 297-316. doi:10.2190/PNOP-RUJR-JUXB-XXQA

Goodhart, F. W., Hsu, J., Baek, J. H., Coleman, A. L., Maresca, F. M., \& Miller, M. B. (2006). A view through a different lens: Photovoice as a tool for student advocacy. Journal of American College Health, 55, 53-56. doi:10.3200/ JACH.55.1.53-56

Gosselink, C. A., \& Myllykangas, S. A. (2007). The leisure experiences of older U.S. women living with HIV/AIDS. Health Care for Women International, 28, 3-20. doi:10.1080/07399330601001402

Gouvernement du Québec. (2013a). Emploi Québec. Retrieved from http://emploiquebec.net/index_en.asp

Gouvernement du Québec. (2013b). Local employment centre locator. Retrieved from http://www.mess.gouv.qc.ca/ services-en-ligne/centres-locaux-emploi/localisateur/index_en.asp

Hergenrather, K. C., Rhodes, S. D., \& Clark, G. (2006). Windows to work: Exploring employment-seeking behaviors of persons with HIV/AIDS through Photovoice. AIDS Education \& Prevention, 18, 243-258. doi:10.1521/ aeap.2006.18.3.243

Hergenrather, K., Rhodes, S., Cowan, C., Bardhoshi, G., \& Pula, S. (2009). Photovoice as community-based participatory research: A qualitative review. American Journal of Health Behavior, 33(6), 686-698. doi:10.1525/jer.2012.7.4.34

Hesse-Biber, S., \& Yaiser, M. (2004). Feminist perspectives on social research. New York: Oxford University Press.

Israel, B. A., Schultz, A., Parker, E., \& Becker, A. (1998). Review of community-based research: Assessing partnership approaches to improve public health. Annual Review of Public Health, 19, 173-202. doi:10.1146/annurev. publhealth.19.1.173

Keiffer, C. H. (1984). Citizen empowerment: A developmental perspective. Prevention in Human Services, 3, 9-36. doi:10.1300/J293v03n02_03

Leipert, B. (2010). Rural and remote women and resilience: Grounded theory and Photovoice variations on a theme. In C. Winters \& H. Lee (Eds.), Rural nursing: Concepts, theory and practice (3rd ed., pp. 105-129). New York: Springer. 
Lockett, D., Willis, A., \& Edwards, N. (2005). Through seniors' eyes: An exploratory qualitative study to identify environmental barriers to and facilitators of walking. Canadian Journal of Nursing Research, 37, 48-65.

Lykes, M. B. (2001). Creative arts and photography in participatory action research in Guatemala. In P. Reason \& H. Bradbury (Eds.), Handbook of action research: Participative inquiry \& practice (pp. 363-371). London, England: Sage.

McIntyre, A. (2003). Through the eyes of women: Photovoice and participatory research as tools for imagining place. Gender, Place, and Culture, 10, 47-66. doi:10.1080/0966369032000052658.

Minkler, M., \& Wallerstein, N. (2003). Introduction to community based participatory research. In M. Minkler \& N. Wallerstein (Eds.), Community-based participatory research for health (pp. 3-26). San Francisco, CA: Jossey-Bass.

Moffitt, P., \& Vollman, A. R. (2004). Photovoice: Picturing the health of Aboriginal women in a remote northern community. Canadian Journal of Nursing Research, 36, 189-201.

Photovoice. (2008). Photography for integration: How to set up your project-planning and management. Retrieved from http://www.photovoice.org/html/pvmethodology/method_01/projects.htm\#participants

Pink, S., Kurti, L., \& Afonso, A. I. (2004). Working images: Visual research and representation in ethnography. London: Routledge.

Plunkett, R., Leipert, B. D., \& Ray, S. L. (2012). Unspoken phenomena: Using the Photovoice method to enrich phenomenological inquiry. London, ON: Blackwell.

Rose, G. (1997). Engendering the slum: Photography in East London in the 1930s. Gender, Place \& Culture, 4(3), 277-301. doi:10.1080/09663699725350

Statistics Canada. (2012). Cinquante ans de familles au Canada : 1961 à 2011. Retrieved from http://www12.statcan. gc.ca/census-recensement/2011/as-sa/98-312-x/98-312-x2011003_1-fra.cfm

Thomas, D. R. (2006). A general inductive approach for analyzing qualitative evaluation data. American Journal of Evaluations, 27, 237-246. doi:10.1177/1098214005283748

Tsey, K., Wilson, A., Haswell-Elkins, M., Whiteside, M., McCalman, J., Cadet-James, Y., \& Wenitong, M. (2007). Empowerment-based research methods: A 10-year approach to enhancing indigenous social and emotional wellbeing. Australasian Psychiatry, 15(Suppl.), S34-S38. doi:10.1080/1039560701701163

Valera, P., Gallin, J., Schuk, D., \& Davis, N. (2010). “Trying to eat healthy”: A Photovoice study about women's access to healthy food in New York City. Journal of Women and Social Work, 24, 300-314. doi:10.1177/0886109909337378

Vandette, M.-P., Valiquette-Tessier, S.-C., \& Gosselin, J. (in press). L'utilisation de Photovoice afin de témoigner de l'expérience de mères monoparentales vivant dans un contexte défavorisé. Nouvelles pratiques sociales.

Vaughn, L. M., Forbes, J. R., \& Howell, B. (2009). Enhancing home visitation programs: Input from a participatory evaluation using Photovoice. Infants and Young Children, 22, 132-145. doi:10.1097/01.IYC.0000348054.10551.66

Villagran, M. (2011). Methodological diversity to reach patients along the margins, in the shadows and on the cutting edge. Patient Education and Counselling, 82, 292-297. doi:10.1016/j.jand.2012.01.011

Wang, C. C. (1999). Photovoice: A participatory action research strategy applied to women's health. Journal of Women's Health, 8, 185-192.

Wang, C. C. (2006). Youth participation in Photovoice as a strategy for community change. Journal of Community Practice, 14, 147-161. doi:10.1300/J125v14n01_09

Wang, C., \& Burris, M. A. (1997). Photovoice: Concept, methodology, and use for participatory needs assessment. Health Education Behavior, 24, 369-387. doi:10.1177/109019819702400309

Wang, C. C., Cash, J. L., \& Powers, L. S. (2000). Who knows the streets as well as the homeless? Promoting personal and community action through Photovoice. Health Promotion Practice, 1, 81-89. doi:10.1177/152483990000100113

Wang, C., Morrel-Samuels, S., \& Pestronk, R. (2004). Flint Photovoice: Community building among youths, adults and policymakers. American Journal of Public Health, 94(6), 911-913. doi:10.2105/AJPH.94.6.911

Wang, C. C., \& Pies, C. A. (2004). Family, maternal, and child health through Photovoice. Maternal \& Child Health Journal, 8, 95-102. doi:10.1023/B:MACI.0000025732.32293.4f

Wilson, N., Minkler, M., Dasho, S., Wallerstein, N., \& Martin, A. (2008). Getting to social action: The Youth Empowerment Strategies (YES!) project. Health Promotion Practice, 9, 395-403. doi:10.1177/1524839906289072

Work Group for Community Health and Development. (2013). Implementing Photovoice in your community. Retrieved November 4, 2013, from http://ctb.ku.edu/en/table-of-contents/assessment/assessing-community -needs-and-resources/photovoice/main 